\title{
Electromyographic preactivation pattern of the gluteus medius during weight-bearing functional tasks in women with and without anterior knee pain
}

Padrão de pré-ativação eletromiográfica do glúteo médio durante atividades
funcionais com descarga de peso em mulheres com e sem dor anterior do joelho

Theresa H. Nakagawa', Thiago B. Muniz', Rodrigo M. Baldon', Carlos D. Maciel2, César F. Amorim³, Fábio V. Serrão

\begin{abstract}
Background: Proximal factors have been proposed to influence the biomechanics of the patellofemoral joint. A delayed or diminished gluteus medius (GM) activation, before the foot contact on the ground during functional activities could lead to excessive femur adduction and internal rotation and be associated with anterior knee pain (AKP). There are few studies on this topic and the results were inconclusive, therefore, it is necessary to investigate the GM preactivation pattern during functional activities. Objective: To compare the GM electromyographic (EMG) preactivation pattern during walking, descending stairs and in single leg jump task in women with and without AKP. Methods: Nine women clinically diagnosed with AKP and ten control subjects with no history of knee injury participated in this study. We evaluated GM EMG linear envelope before the foot contact on the ground during walking and GM onset time and EMG linear envelope during descending stairs as well as in a single leg vertical jump. Mann-Whitney $U$ tests were used to determine the between-group differences in GM EMG preactivation pattern. Results: No between-group differences were observed in GM linear envelope during walking $(P=0.41)$, GM onset time and linear envelope during descending stairs $(P=0.17$ and $P=0.15)$ and single leg jump ( $P=0.81$ and $P=0.33$ ). Conclusions: Women with AKP did not demonstrated altered GM preactivation pattern during functional weight bearing activities. Our results did not support the hypothesis that poor GM preactivation pattern could be associated with AKP. Article registered in the Australian New Zealand Clinical Trials Registry (ANZCTR) under the number ACTRN12610000115033.
\end{abstract}

Kew words: anterior knee pain; hip muscle; surface EMG.

\section{Resumo}

Contextualização: Tem sido proposto que fatores proximais influenciam a biomecânica da articulação fêmoro-patelar. Um atraso ou diminuição da ativação do glúteo médio (GM) antes do contato do pé no solo, durante atividades funcionais, poderia levar a adução e rotação interna excessiva do fêmur e provocar a dor anterior do joelho (DAJ). Existem poucos estudos sobre o assunto, e os resultados não foram conclusivos; assim, há necessidade de estudar a pré-ativação do GM durante atividades funcionais. Objetivo: Comparar o padrão de pré-ativação eletromiográfica (EMG) do GM durante a caminhada, descida de degraus e salto unipodal entre mulheres com e sem DAJ. Métodos: Nove mulheres com diagnóstico clínico de DAJ e dez mulheres sem história de lesão no joelho participaram do estudo. Avaliou-se a envoltória linear do sinal EMG do GM antes do contato do pé no solo, durante caminhada; o tempo de ativação do GM e a envoltória linear do sinal EMG durante descida de degraus e salto unipodal. Utilizou-se o teste Mann-Whitney para determinar a diferença intergrupos no padrão de pré-ativação EMG do GM. Resultados: Não se encontrou nenhuma diferença intergrupos na envoltória linear do GM durante caminhada $(P=0.41)$, no tempo de ativação e na envoltória linear, durante descida de degraus $(P=0.17$ e $P=0.15$ ) e salto unipodal ( $P=0.81$ e $P=0.33$ ). Conclusões: Mulheres com DAJ não apresentaram alterações significativas no padrão de pré-ativação do GM durante atividades funcionais. Os presentes resultados não sustentam a hipótese de que o pobre padrão de pré-ativação do GM esteja envolvido na DAJ

Artigo registrado no Australian New Zealand Clinical Trials Registry (ANZCTR) sob o número ACTRN12610000115033.

Palavras-chave: dor anterior do joelho; musculatura do quadril; EMG de superfície.

Received: 19/02/2010 - Revised: 04/06/2010 - Accepted: 01/10/2010

\footnotetext{
Physical Therapy Department, Universidade Federal de São Carlos (UFSCar), São Carlos, SP, Brazil

2Electrical Engineering Department, Universidade de São Paulo (USP), São Carlos, SP, Brazil

${ }^{3}$ Mechanical Engineering Department, Universidade Estadual Paulista (UNESP), Guaratinguetá, SP, Brazil

Correspondência para: Fábio V. Serrão, Universidade Federal de São Carlos, Departamento de Fisioterapia, Rod. Washington Luís, km 235, CEP 13565-905, São Carlos, SP, Brasil,

e-mail: fserrao@ufscar.br
} 


\section{Introduction $: \because \therefore$}

Anterior knee pain (AKP) is a common musculoskeletal condition ${ }^{1}$. It affects predominantly female athletes ${ }^{2}$ and represents approximately $25 \%$ of the knee joint conditions treated in sports clinics ${ }^{1}$. AKP patients present insidious and diffuse anterior knee pain that is aggravated during ascending or descending stairs, squatting as well as by prolonged sitting. ${ }^{3}$. The etiology of AKP is multifactorial and it is still not clear ${ }^{4-6}$.

Recently, proximal factors, such as hip muscle strength and kinematics,have been proposed to influence the biomechanics of the patellofemoral joint ${ }^{7-9}$. During weight bearing activities the hip abductors and external rotators muscles must act eccentrically to control the femur adduction and internal rota$\operatorname{tion}^{10}$. Excessive femur adduction leads to the knee valgus and can increase the lateral forces acting on the patella. Internal rotation of the femur may lead to excessive lateral gliding of the patella and increases the contact pressure of the patella on the lateral femoral condyle ${ }^{5,11}$. Therefore, a poor hip muscle eccentric strength control can lead to femur adduction and internal rotation during functional activities which causes stress on the patellofemoral joint and might be associated with the AKP.

Hip abductors and external rotators muscle weakness have been reported in women with $\mathrm{AKP}^{7,9,12}$. Also, the association between hip muscle strength and hip kinematic during functional activities has been studied in women with $\mathrm{AKP}^{13}$. Bolgla et al. ${ }^{14}$ reported significant hip muscle weakness in women with AKP but no altered hip kinematics during stair descent. On the other hand, some authors ${ }^{15,16}$ demonstrated diminished hip abduction strength and increased hip adduction during single-legged jump and running in women with AKP. Powers and Souza ${ }^{17}$ described an increased hip internal rotation accompanied by decreased hip extensor strength during weight bearing activities. The literature seems to support that hip muscle weakness play a role in the AKP and it may be associated with hip altered kinematic during functional activities.

Poor hip neuromuscular control could also influence the control of femur adduction or internal rotation during functional activities causing excessive stress on the patellofemoral joint. In fact, the hip muscles especially the gluteus medius (GM) activation pattern have been investigated in patients with AKP. Brindle, Mattacola and McCrory ${ }^{18}$ reported a delayed GM electromyographic (EMG) onset during stair ascent and shorter durations of activation for stair ascent and descent in subjects with AKP. Cowan, Crossley and Bennell ${ }^{19}$ demonstrated a delayed activation of GM during a stair stepping task. However, Boling et al. ${ }^{20}$ did not find differences in GM EMG onset or in the duration during stair stepping task in the AKP group. Powers and Souza ${ }^{17}$ studied GM EMG signal amplitude during functional activities, but did not find differences between women with
AKP and controls. Based on the results above, the role of the GM neuromuscular control in AKP is still inconclusive.

Although some studies have suggested altered GM neuromuscular control in patients with AKP ${ }^{18,19}$, these studies only evaluated the overall GM EMG activity; in addition studies that focused on parameters of the GM EMG preactivation (i.e. EMG activity before the foot contact on the floor) during functional activities were not found. Preparatory and reflexive muscle activation are two neuromuscular processes that contribute to joint stability ${ }^{21}$. The former neuromuscular strategy depends on feedforward motor control of the central nervous system ${ }^{22}$ and may have a major function in joint protection ${ }^{23}$. The pre activation of the muscles surrounding a joint may be involved in the control of the position of the limb before a stressful event and also increase the responsiveness of these muscles to provide dynamic stability ${ }^{21}$. Theoretically, both an increased and faster GM preactivation could position the lower limb with an appropriate alignment and prevent hip kinematic alterations, such as excessive hip adduction and internal rotation, and consequently, will avoid excessive patellofemoral stress. The understanding of the GM EMG preactivation is important because neuromuscular training for prevention and treatment of patients with AKP may involve training to modify the activation pattern of this muscle before the foot strike to prevent hip altered kinematic during functional activities.

Therefore, the objective of this study was to compare the GM EMG preactivation pattern between women with and without AKP. More specifically, we compared the GM EMG linear envelope before foot contact during walking, descending stairs and single leg jump, and also GM EMG onset time during descending stairs and single leg jump in women with AKP and healthy controls. It was hypothesized that women with AKP would demonstrate delayed GM onset time and diminished GM EMG signal amplitude during the evaluated activities.

\section{Methods $: \because$.}

\section{Subjects}

This case-control study included 19 women aged from 18 to 35 years. We recruited nine participants clinically diagnosed with AKP who were referred to the physical therapy clinic from the Universidade Federal de São Carlos (UFSCar), São Carlos, SP, Brazil (age $=23.33 \pm 5.29$ years; height $=1.65 \pm 0.07 \mathrm{~m}$; body mass $=61.39 \pm 10.19 \mathrm{~kg}$ ). Ten matched participants controlled for gender, age, height and body mass from the same UFSCar with no history of previous knee injury or pain (age $=22.70 \pm 2.45$ years; height $=1.63 \pm 0.06 \mathrm{~m}$; body mass $=56.00 \pm 3.52 \mathrm{~kg}$ ) were also recruited. 
Inclusion criteria for the AKP group were as it follows: (1) anterior or retropatellar knee pain while performing at least three of the following activities: ascending/descending stairs, squatting, running, kneeling, hopping/jumping and prolonged sitting; (2) insidious onset of symptoms unrelated to a traumatic event; (3) pain duration of at least four weeks; and (4) presence of pain during the palpation of the patellar facets, on stepping down from a 25-cm step, or during a double-legged squat ${ }^{24,25}$.

Inclusion criteria for the control group were as it follows: (1) no history of knee pain or diagnosis of knee conditions or trauma; (2) absence of pain on the knee during palpation and (3) absence of knee pain with any of the activities described for the individuals in the AKP group ${ }^{17}$.

Subjects from the AKP and control groups were excluded if they showed signs or symptoms of any of the following: (1) meniscal or other intra-articular pathological conditions; (2) cruciate or collateral ligament involvement; (3) tenderness of the patellar tendon, iliotibial band, or pes anserinus tendons; (4) patellar apprehension sign; (5) Osgood-Schlatter or Sinding-Larsen-Johansson syndromes; (6) hip pain; (7) back pain; (8) sacroiliac joint pain; (9) history of patellar dislocation; (10) evidence of a knee joint effusion; or (11) previous surgery of the patellofemoral joint ${ }^{12,25}$.

For each subject one limb was used for the between-group comparison. The patient's self-reported most affected side was considered to be the involved side for subjects with bilateral symptoms ${ }^{12}$. The most affected side was considered to be the most painful and limited during functional activities according to the patient's perception. The corresponding limb of the control subject was tested.

Prior to participation, all subjects signed an informed consent approved by the Institutional Review Board at UFSCar, São Carlos, SP, Brazil, where it was carried out under protocol number 219/2006.

\section{Procedures}

\section{Anterior Knee Pain Scale (AKPS)}

A self-administered AKPS was completed by the AKP patients to better describe their knee function. The AKPS is 13-item questionnaire with a maximum total score of 100 indicating no disability. This tool is a validated and responsive outcome measure of treatment of $\mathrm{AKP}^{26,27}$, however, it is not validated and adapted into Portuguese.

\section{GM EMG preactivation pattern}

Subjects reported to the Musculoskeletal Laboratory for a single testing session. Prior to testing, subjects performed a 5-minute warm-up walking on a treadmill ${ }^{28}$ (Proaction BH Fitness Explorer) at a $1.66 \mathrm{~ms}^{-1}$ speed. Before electrode placement, the skin was shaved, abraded and cleaned with isopropyl alcohol. Bipolar Ag/AgCl surface electrodes (Meditrace TM 100, Mansfield, Canada, CA) were placed one-half of the distance between the iliac crest and the greater trochanter ${ }^{29}$, and also midway between the anterior and posterior superior iliac spines $^{30}$ over the muscle belly of the GM. Surface electrodes, placed parallel to the GM muscle fibers, measured $30 \mathrm{~mm}$ in diameter and had an interelectrode distance of $30 \mathrm{~mm}$. The reference electrode was positioned on the radial styloid process on the same side of the evaluated lower limb.

EMG signals as well as the footswitch data were obtained using an eight channel module (EMG Systems), consisting of a signal conditioner with a band pass filter with cut-off frequencies at $20-500 \mathrm{~Hz}$, an amplifier gain of x1000 and a common mode rejection ratio $>120 \mathrm{~dB}$. The data underwent an analog to digital conversion (12 bits) with a sampling frequency of anti-aliasing $>1000 \mathrm{~Hz}$ and input range of $5 \mathrm{mV}$. The raw EMG data were stored on a personal computer for analysis with a custom program in Matlab ${ }^{\odot}$ (Mathworks, Natick, Massachusetts, USA).

The maximal voluntary isometric contraction (MVIC) for the GM to normalize the raw EMG data was performed using an isokinetic dynamometer (Biodex Multi-Joint System 2, Biodex Medical Incorporation, New York, USA). GM MVIC was measured with the subject positioned on a side lying position ${ }^{31}$. The dynamometer's axis rotation was aligned with a point on the subject representing the intersection of two straight lines. One line was directed inferiorly from the posterior superior iliac spine toward the knee, and the other line was directed from the greater trochanter of the femur toward the midline of the body. The lever arm of the dynamometer was attached with straps five centimeters above the superior patella border. The hip was placed in a position that was neutrally aligned in all three planes. Subjects completed two sets of 5 seconds for the GM MVIC. Rest intervals of one minute were given between trials. The EMG signal collected during the second trial was used to normalize the signal collected during functional activities.

To determine the foot contact with the ground during the evaluated activities, a footswitch (EMG Systems) was placed in each subject's shoe of the lower extremity being tested. The footswitch was placed under the rear foot during the walking test and under the forefoot during the descending stairs and single leg jumping tests. The GM EMG evaluation during walking, descending stairs and single leg jump was conducted in a random order.

During the walking test, the subjects walked during $1 \mathrm{mi}-$ nute, to familiarize themselves with the evaluated activity, on a motor driven treadmill matching a cadence of $117 \mathrm{steps} / \mathrm{min}^{32}$ monitored with a digital metronome (Quick Time QT-05). After a 3 minutes rest interval, we collected the GM EMG activity while the subjects walked during 1 minute. 
The descending stairs activity was evaluated in a 3 steps custom made stairs with a height of $20 \mathrm{~cm}$ and depth of $27.5 \mathrm{~cm}^{33}$. Subjects stood at the top of the stairs and after the command "ready, set, go", the subjects were instructed to step down first with their evaluated limb at a rate of 154 steps $/ \mathrm{min}^{33}$ controlled by a digital metronome. Subjects performed 3 descending stairs trial to familiarize themselves with the procedure and, after 3 minutes rest interval, GM EMG data was collected during 2 trials with a rest interval of 1 minute between them. Only data for the first step down were analyzed.

To evaluate the single leg vertical jump, the subjects performed 3 single leg jumps as high as possible after the verbal command "ready, set, go" to familiarize themselves with the test and, after 3 minutes of rest interval, GM EMG activity was collected during 3 single leg jumps with one minute rest interval between each test. Subjects were asked to begin the single leg jump with the non-evaluated limb and to land with the evaluated limb. The subjects were asked to maintain the hands behind their back during this test.

\section{EMG analysis}

All EMG files were pre-filtered with a 101th-order FIR ( finite impulse response) bandpass filter with passband 20-500 Hz. The envelope was estimated from a full-wave rectified filtered signal using a lowpass 101th-order FIR filter with cut-off frequency of $15 \mathrm{~Hz}$ and a Hamming window. Muscle onset was determined when EMG activity increased above a threshold at least two standard deviations above EMG data for a resting interval prior

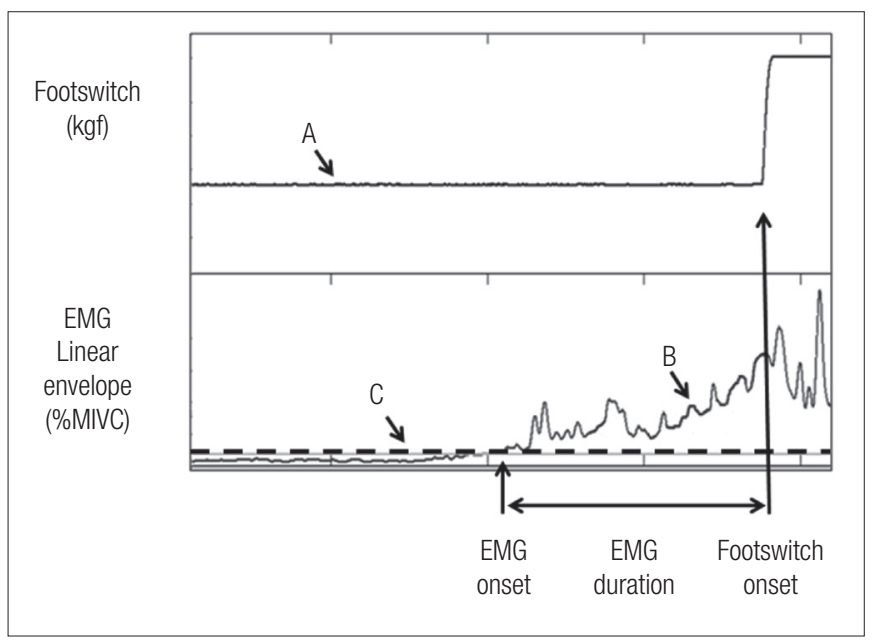

Figure 1. Example of temporal relationship between footswitch signal (line A) and EMG signal (line B). GM onset time is prior to foot contact. EMG duration is the time between EMG onset and footswitch onset. Linear envelope is calculated as the area under the curve during the EMG duration and is expressed as a percentage of the MVIC. Line C (dashed line) represented the two standard deviations threshold above electromyography data for a resting interval prior to contraction from GM. to contraction from GM of $200 \mathrm{~ms}$ and remained above this threshold for at least $25 \mathrm{~ms}$. The muscle was considered off when it fell below this threshold for more than $50 \mathrm{~ms}^{4}$. The GM onset was determined using the procedures described above.

To evaluate the magnitude of GM EMG activation during walking we selected six consecutive stride windows from the middle of the 1 minute EMG data. The integrated EMG during a stride was obtained between two consecutive footswitch signals which represented two rear foot initial contacts on the ground with the evaluated lower limb. The EMG data were time normalized with the gait cycle taken as $100 \%$. The magnitude of GM activity was computed from the area under the linear envelope for the duration of muscular activity during a stride and it was expressed as a percentage of the MVIC during one second. We used the mean value from the six strides to express the magnitude of GM activity during walking ${ }^{34}$.

We evaluated the onset time from GM and the magnitude of muscular preactivity on the functional activities, descending stairs and single leg jump. The time of preactivation from GM was considered to be the time interval between the GM EMG onset and the footswitch onset time (which represented the initial contact of the foot with the floor) (Figure 1). The EMG data were time normalized considering 0\% the GM onset time and $100 \%$ the footswitch onset time. The magnitude of GM preactivation time was computed from the area under the linear envelope for the duration of muscular activity and it was expressed as a percentage of the MVIC during one second ${ }^{18}$.

\section{Data analysis}

Statistical analyses were performed using SPSS for Windows, version 10.0 (SPSS Inc, Chicago, IL). Independent $t$ tests were used to compare demographics and clinical characteristics data between AKP and control groups. Shapiro-Wilk test indicated that the GM EMG activity data were not all normally distributed. Mann-Whitney $U$ tests were used to compare GM EMG activity during walking, descending stairs and single leg vertical jump between AKP and matched control subjects. The alpha level for the comparisons was set at 0.05 .

\section{Results $: \because$ 。}

Demographic and clinical characteristics of the AKP and the matched control groups are presented in Table 1. The evaluated groups did not differ in their demographic and clinical characteristics.

The GM EMG preactivation linear envelope expressed as a percentage of maximal isometric voluntary contraction during walking $(P=0.41)$, descending stairs $(P=0.15)$ and single leg 
Table 1. Demographic and clinical characteristics of AKP and control groups.

\begin{tabular}{lccc}
\hline Patient Description & AKP $(\mathrm{n}=9)$ & Control $(\mathrm{n}=10)$ & P value \\
\hline Age $(\mathrm{y})^{*}$ & $23.3(5.2)$ & $22.7(2.5)$ & 0.72 \\
\hline Height $(\mathrm{cm})^{\star}$ & $165.2(7.3)$ & $163.4(5.5)$ & 0.52 \\
\hline Body mass $(\mathrm{kg})^{\star}$ & $61.4(10.2)$ & $56.0(3.5)$ & 0.11 \\
\hline AKPS score & $73.2(8.9)$ & $\mathrm{n} / \mathrm{a}$ & \\
\hline${\text { Symptom duration }(\mathrm{mo})^{\star}}^{*}$ & $52.1(46.7)$ & $\mathrm{n} / \mathrm{a}$ & \\
\hline
\end{tabular}

AKPS=Anterior Knee Pain Scale; $n / a=n o t$ applicable; AKP=anterior knee pain. * Mean (SD); ${ }^{\dagger}$ Anterior Knee Pain Scale (range from 0 to 100 , with higher scores indicating greater function and lower pain levels) ${ }^{11}$.

Table 2. GM electromyographic preactivation pattern during walking, descending stairs and single leg vertical jump: between-group comparisons.

\begin{tabular}{|c|c|c|c|c|}
\hline & AKP Mean (SD) & Control Mean (SD) & $P$ value ${ }^{*}$ & Difference $(95 \% \mathrm{Cl})^{\top}$ \\
\hline \multicolumn{5}{|l|}{ Walking } \\
\hline Linear envelope (\%MVIC) & $3.1(2.5)$ & $2.2(2.2)$ & 0.41 & $0.9(-1.4-3.2)$ \\
\hline \multicolumn{5}{|l|}{ Descending stairs } \\
\hline Onset time (ms) $\ddagger$ & $-103.5(79.3)$ & $-125.7(84.1)$ & 0.17 & $-27.0(-107.9-53.9)$ \\
\hline Linear envelope (\%MVIC) & $5.7(3.6)$ & $3.0(1.3)$ & 0.15 & $2.8(78-5.41)$ \\
\hline \multicolumn{5}{|l|}{ Single leg vertical jump } \\
\hline Onset time (ms)‡ & $-172.5(89.3)$ & $-169.2(112.6)$ & 0.81 & $-3.3(-98.9-92.2)$ \\
\hline Linear envelope (\%MVIC) & $14.4(10.7)$ & $10.1(8.0)$ & 0.33 & $-5.9(-14.3-2.4)$ \\
\hline
\end{tabular}

$\mathrm{Cl}=$ confidence interval; $\mathrm{MVIC}=$ maximal voluntary isometric contraction; $\mathrm{AKP}=$ anterior knee pain. *Mann-Whitney $\mathrm{U}$ test for between-group differences. ${ }^{\dagger}$ Mean between-group differences. $\mathrm{FGM}$ onset time prior to foot contact is indicated by negative values.

vertical jump $(P=0.33)$ did not demonstrate statistical significant difference between the studied groups. Also, the GM onset time during descending stairs $(P=0.17)$ and single leg vertical jump $(P=0.81)$ did not demonstrate difference between AKP and control groups (Table 2).

\section{Discussion $: \because$.}

Since GM is an important stabilizer of the femur movement in the frontal and transversal plane ${ }^{18}$, a delayed GM onset or a diminished activation before the foot contact on the floor leading to excessive femur adduction and internal rotation could be associated with $A K P^{5,8,11,19}$. Few studies have focused on the role of GM activation pattern during weight bearing activities and the results were inconclusive $\mathrm{e}^{17-20}$.

It has been demonstrated that women present altered hip and knee kinematic and EMG preactivation during the preparation phase, i.e. before landing on a vertical stop-jump ${ }^{35}$. However, we are not aware of any study that focused on the GM EMG preactivation during functional activities in subjects with AKP. We were interested to investigate the muscle preactivation because it has an important role on the dynamic stabilization of the joint by positioning the lower extremity with an appropriate alignment before the foot contact on the ground, besides a muscle has a short reaction time after the contact floor to correct any possibly altered kinematics ${ }^{36}$. So, it is important to understand GM EMG preactivation patterns to design neuromuscular training for prevention and treatment of AKP.

We studied weight bearing activities with progressively greater external loads. It was supposed that altered neuromuscular control would be more apparent as the activities became more demanding. Our results did not reveal differences as the demand of activity increased. Nadeau et al. ${ }^{32}$ mentioned diminished hip moments in the frontal plane during walking in AKP patients, however, the authors did not demonstrated statistical analysis appropriately. In our study there was no difference in the GM amplitude signal during walking in women with and without AKP. We are not aware of any other study that evaluated GM activity during walking for comparison of our results. Based in our results, the intensity of GM activation is not altered in the women with AKP during walking.

During descending stairs, we found no difference in the GM onset or intensity of preactivation between the groups studied. Although it was not found any study that evaluated specifically the GM EMG preactivation in AKP subjects descending stairs, our results are in accordance to Boling et al. ${ }^{20}$ that reported no statistical difference in the GM onset when ascending and descending stairs in AKP subjects. Powers and Souza ${ }^{17}$ reported decreased hip torque production, greater peak hip internal rotation and significantly greater gluteus maximus recruitment in individuals in the AKP group; however, there was no difference 
in the GM signal amplitude during weight bearing activities. Brindle, Mattacola and McCrory ${ }^{18}$ demonstrated delayed GM onset and shorter durations during stair ascent and shorter GM duration during stair descent. Our results are in agreement with the cited literature, because although Brindle, Mattacola and $\mathrm{McCrory}^{18}$ reported altered GM neuromuscular control, they found no differences in the GM EMG onset or amplitude during its eccentric activity. However, our results are not in agreement with Cowan, Crossley and Bennell ${ }^{19}$ which reported that AKP subjects presented a delayed onset GM during a stepping task. One possible reason for the lack of difference in the GM preactivation between the studied groups may be related to the fact that descending stairs was not a sufficient demand task to elicit differences on the evaluated parameters. Also, hip kinematics studies from Bolgla et al. ${ }^{14}$ and Powers and Souza ${ }^{17}$ did not demonstrated an increased hip adduction during stair descent, although both of them identified hip abductor muscle weakness in women with AKP. We did not evaluated hip kinematics in our study, but we speculate that it is possible that during stair descent there was no excessive hip adduction to be controlled in the AKP group when compared to healthy subjects and the GM activity was not altered.

Contrary to our initial hypothesis, the GM activation pattern was not altered in women with AKP during a single leg jump, which was the most demanding task evaluated in our study. We are not aware of any study that evaluated GM EMG during this task in the AKP group for comparison of results. But, it has been reported ${ }^{15,37}$ that women with AKP demonstrated greater hip adduction, decreased hip internal rotation and lower hip abduction and external rotation strength during and after an exertion protocol of repetitive single leg jumps. So, based on our results and the literature, women with AKP seems to present altered kinematics during single leg jumps associated with hip muscle weakness but not to present altered GM preactivity.

This study had several limitations. Firstly, the high variability of our measures may have accounted for the finding of no difference between the studied groups. It is likely that with a larger sample size some of our results might show differences between the groups, also we did not conducted a priori sample size calculation. The AKP subjects evaluated in this study had only mild disability ${ }^{26}$; based on the mean AKPS score of 73.2, which could have account for the lack of difference between groups. The functional activities of walking and descending stairs were relatively simple tasks and maybe more demanding tasks were necessary to elicit an altered GM neuromuscular control. Other studies that evaluated single leg jump task in AKP subjects performed repetitive jumps ${ }^{15,33}$ which could be more challenging than our protocol. We only evaluated GM, but different hip muscles also act as stabilizers of the femur during weight bearing activities, such as gluteus maximus and the tensor fasciae latae. So, future research using a larger sample size, evaluating more demanding functional tasks, different hip muscles is necessary to evaluate the role of hip muscle activation pattern in AKP.

\section{Conclusion $: \because$.}

GM EMG onset time and signal amplitude before the foot contact on the ground is not altered in women with AKP during walking, descending stairs and single leg jump when compared to healthy controls. Our results did not support the hypothesis that poor GM preactivation pattern could be involved in AKP. Future studies should investigate GM and other hip muscles EMG preactivation pattern during more demanding activities. It is important to understand the hip and knee neuromuscular control before the foot contact on the ground since it could cause altered motion pattern leading to adverse effects on the patellofemoral joint and should be considered in the evaluation, prevention and treatment of AKP.

\section{Acknowledgements $: \because$.}

We gratefully acknowledge the financial support from the Conselho Nacional de Desenvolvimento Científico e Tecnológico (CNPq) and Fundação de Amparo à Pesquisa do Estado de São Paulo (FAPESP).

\section{References $: \because$.}

1. Devereaux MD, Lachmann SM. Patello-femoral arthralgia in athletes attending a sports injury clinic. Br J Sports Med. 1984;18(1):18-21.

2. Fulkerson JP, Arendt EA. Anterior knee pain in females. Clin Orthop Relat Res. 2000;372:69-73.

3. Heintjes E, Berger MY, Bierna-Zeinstra SM, Bernsen RM, Verhaar JA, Koes BW. Exercise therapy for patellofemoral pain syndrome. Cochrane Database Syst Rev. 2003;(4):CD003472.

4. Cowan SM, Hodges PW, Bennell K, Crossley KL. Altered vastii recruitment when people with patellofemoral pain syndrome complete a postural task. Arch Phys Med Rehabil. 2002;83(7):989-95.
5. Lee $T Q$, Morris G, Csintalan RP. The influence of tibial and femoral rotation on patellofemoral contact area and pressure. J Orthop Sports Phys Ther. 2003;33(5):686-93.

6. Serrão FV, Cabral CMN, Bérzin F, Candolo C, Monteiro-Pedro V. Effect of tíbia rotation on the electromyographical activity of the vastus medialis oblique and vastus lateralis longus muscles during isometric leg press. Phys Ther Sports. 2005;6(1):15-23.

7. Ireland ML, Davis IS, Ballantyne BT, Willson JD. Hip strength in females with and without patellofemoral pain. J Orthop Sports Phys Ther. 2003;33(11):671-6. 
8. Powers CM. The influence of altered lower-extremity kinematics on patellofemoral joint dysfunction: a theoretical perspective. J Orthop Sports Phys Ther. 2003;33(11):639-46.

9. Robinson RL, Nee RJ. Analysis of hip strength in females seeking physical therapy treatment for unilateral patellofemoral pain syndrome. J Orthop Sports Phys Ther. 2007;37(5):232-7.

10. Ferber R, Davies IM, Williams DS 3rd. Gender differences in lower extremity mechanics during running. Clin Biomech (Bristol, Avon). 2003;18(4):350-7.

11. Powers CM, Ward SR, Fredericson M, Guillet M, Shellock FG. Patellofemoral kinematics during weigth-bearing and non-weigth-bearing knee extension in persons with lateral subluxation of the patella: a preliminary study. J Orthop Sports Phys Ther. 2003;33(11):677-85.

12. Cichanowski HR, Schmitt JS, Johnson RJ, Niemuth PE. Hip strength in collegiate female athletes with patellofemoral pain. Med Sci Sports Exerc. 2007;39(8):1227-32.

13. Mascal CL, Landel R, Powers C. Management of patellofemoral pain targeting hip, pelvis, and trunk muscle function: 2 case reports. J Orthop Sports Phys Ther. 2003;33(11):647-60.

14. Bolgla LA, Malone TR, Umberger BR, Uhl TL. Hip strength and hip and knee kinematics during stair descent in females with and without patellofemoral pain syndrome. J Orthop Sports Phys Ther. 2008;38(1):12-8.

15. Wilson JD, Binder-Macleod S, Davis IS. Lower extremity jumping mechanics of female athletes with and without patellofemoral pain before and after exertion. Am J Sports Med. 2008;36:1587-96.

16. Dierks TA, Manal KT, Hamill J, Davis IS. Proximal and distal influences on hip and knee kinematics in runners with patellofemoral pain during a prolonged run. J Orthop Sports Phys Ther. 2008;38(8):448-56.

17. Powers CM, Souza RB. Differences in hip kinematics, muscle strength, and muscle activation between subjects with and without patellofemoral pain. J Orthop Sports Phys Ther. 2009;39(1):12-9

18. Brindle TJ, Mattacola C, McCrory J. Electromyographic changes in the gluteus medius during stair ascent and descent in subjects with anterior knee pain. Knee Surg Sports Traumatol Arthrosc. 2003;11(4):244-51.

19. Cowan SM, Crossley KM, Bennell KL. Altered hip and trunk muscle function in individuals with patellofemoral pain. Br J Sports Med. 2009;43(8):584-8.

20. Boling MC, Bolgla LA, Mattacola CG, Uhl TL, Hosey RG. Outcomes of a weight-bearing rehabilitation program for patients diagnosed with patellofemoral pain syndrome. Arch Phys Med Rehabil. 2006;87(11):1428-35

21. DeMont RG, Lephart SM. Effect of sex on preactivation of the gastrocnemius and hamstring muscles. Br J Sports Med. 2004;38(2):120-4.

22. Konradsen L, Voigt M, Højsgaard C. Ankle inversion injuries: the role of the dynamic defense mechanism. Am J Sports Med. 1997;25(1):54-8.
23. Bergenheim M, Johansson $H$, Pedersen J. The role of the gamma-system for improving information transmission in populations of la afferents. Neurosci Res. 1995;23(2):207-15.

24. Cowan SM, Bennell KL, Crossley KM, Hodges PW, McConnell J. Physical therapy alters recruitment of the vasti in patellofemoral pain syndrome. Med Sci Sports Exerc 2002;34(12):1879-85.

25. Crossley K, Bennell K, Green S, Cowan S, McConnell J. Physical therapy for patellofemoral pain: a randomized, double-blinded, placebo-controlled trial. Am J Sports Med. 2002;30(6):857-65.

26. Crossley KM, Bennell KL, Cowan SM, Green S. Analysis of outcome measures for persons with patellofemoral pain: which are reliable and valid? Arch Phys Med Rehabil. 2004;85(5):815-22.

27. Kujala UM, Jaakkola LH, Koskinen SK, Taimela S, Hurme M, Nelimarkka O. Scoring of patellofemoral disorders. Arthroscopy. 1993;9(2):159-63.

28. Matsas A, Taylor N, McBurney $\mathrm{H}$. Knee joint kinematics from familiarised treadmill walking can be generalised to overground walking in young unimpaired subjects. Gait Posture. 2000;11(1):46-53

29. Hermens HJ, Freriks B, Merletti R, Hägg GG, Stegeman D, Blok J, et al. SENIAM 8: European recommendations for surface electromyography. Netherlands: Roessingh Research and Development; 1999.

30. Lyons K, Perry J, Gronley JK, Barnes L, Antonelli D. Timing and relative intensity of hip extensor and abductor muscle action during level and stair ambulation. An EMG study. Phys Ther 1983:63(10):1597-605

31. Dvir Z. Isokinetics: muscle testing, interpretation and clinical applications. New York: Churchi Livingstone; 1995

32. Nadeau S, Gravel D, Hébert LJ, Arsenault AB, Lepage Y. Gait study of patients with patellofemora pain syndrome. Gait Posture. 1997;5(1):21-7.

33. Brechter $\mathrm{JH}$, Powers CM. Patellofemoral joint stress during stair ascent and descent in persons with and without patellofemoral pain. Gait Posture. 2002;16(2):115-23.

34. Arsenault AB, Winter DA, Marteniuk RG, Hayes KC. How many strides are required for the analysis of electromyographic data in gait? Scand J Rehabil Med. 1986;18(3):133-5.

35. Chappell JD, Creighton RA, Giuliani C, Yu B, Garret WE. Kinematics and electromyography of landing preparation in vertical stop-jump: risks for noncontact anterior cruciate ligament injury. Am J Sports Med. 2007;35(2):235-41.

36. Wikstrom EA, Tillman MD, Chmielewski TL, Borsa PA. Measurement and evaluation of dynamic joint stability of the knee and ankle after injury. Sports Med. 2006;36(5):393-410.

37. Willson JD, Davis IS. Lower extremity mechanics of females with and without patellofemora pain across activities with progressively greater task demands. Clin Biomech (Bristol, Avon). 2008;23(2):203-11. 